\title{
Isotopic measurements on zircons from Japanese granitic rocks*
}

\author{
PhIliP O. Banks ${ }^{1}$ and Nobumichi Shimizu ${ }^{2}$ \\ Department of Geology, Case Western Reserve University, \\ Cleveland, Ohio, U.S.A. ${ }^{1}$ and Geological Institute, \\ Faculty of Science, University of Tokyo, \\ Tokyo, Japan ${ }^{2}$
}

(Received February 19, 1969; in revised form June 5, 1969)

\begin{abstract}
U-Pb isotopic analyses of zircons from two granodiorites of the Abukuma Plateau indicate a period of plutonic activity in that area approximately $110 \mathrm{~m} . y$. ago. Zircons from two granodiorites of the Shidara area have anomalously high ${ }^{207} \mathrm{~Pb} /{ }^{206} \mathrm{~Pb}$ ratios, resulting from older radiogenic lead acquired during generation or emplacement of the magmas. The inherited component has a minimum age of about $600 \mathrm{~m}$. y. and probably is considerably older. Two periods of emplacement are suggested for the Shidara granodiorites, one at $70-75 \mathrm{~m} . \mathrm{y}$. and the other at perhaps $80-90 \mathrm{~m}$.y.
\end{abstract}

\section{INTRODUCTION}

This study was undertaken as a preliminary step toward establishing a precise chronology for emplacement of the abundant granitic rocks, generally of Cretaceous age, that border the Pacific basin. The isotopic $\mathrm{U}-\mathrm{Pb}$ method of geochronology has satisfactory resolution for this purpose but has not been widely applied to rocks of such young age. In addition, comparisons between $\mathrm{U}-\mathrm{Pb}$ and other radiometric ages have become highly desirable to evaluate problems arising from the secondary behavior of the isotope systems.

$\mathrm{U}-\mathrm{Pb}$ analyses of zircons from four granodiorite plutons of the Ryoke-Abukuma metamorphic belt are reported here. From the Abukuma Plateau we sampled the Miyamoto granodiorite (AM-6501) and Tabito granodiorite (AT-16501). Both are classed as "older" (synkinematic) types on the basis of field evidence, and have been thought to be possibly pre-Cretaceous in age (Goral, 1944; WaTANABE et al., 1955). The granodiorites of the Shidara area are represented by the Kiyosaki granodiorite (RK-16501 and RK-16502) and the Mitsuhashi granodiorite (RM-16501); the former was classed as "older" and the latter as "younger" by KoIDE (1958). Approximate sample locations are shown in Figure 1. SHImizu (1967) has reported lead isotope

\footnotetext{
* Contribution No.49, Department of Geology, Case Western Reserve University.
} 


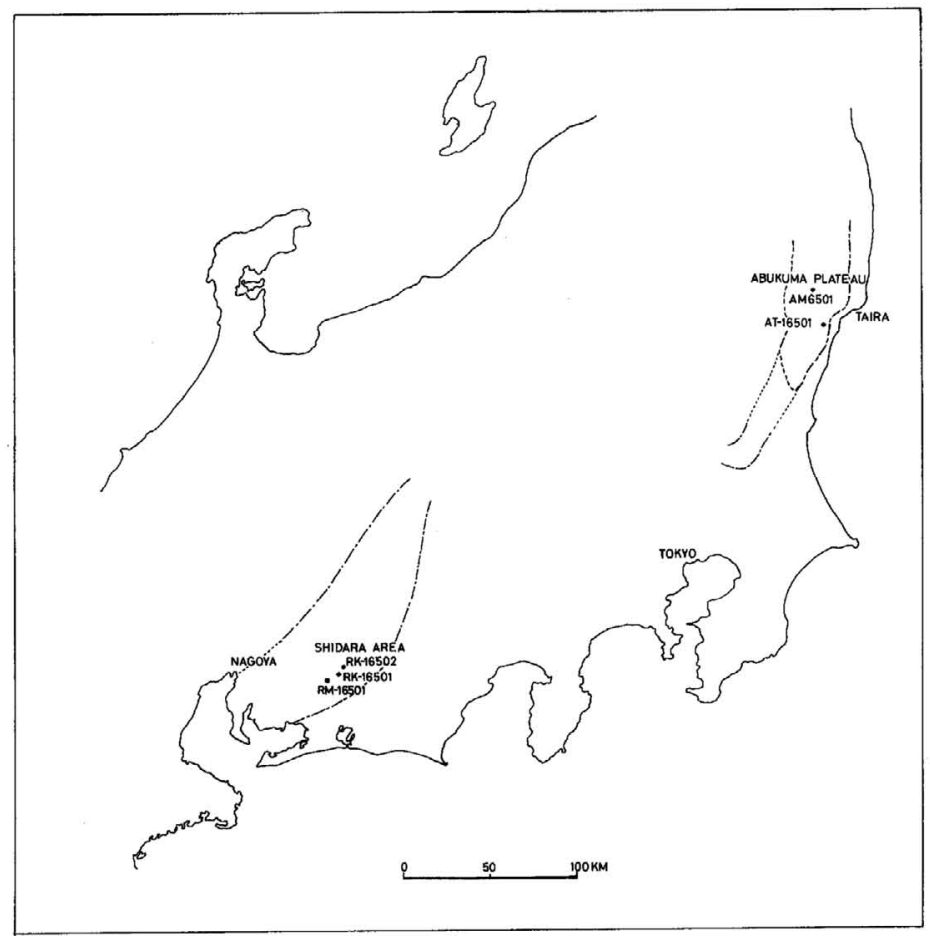

Fig.1. Distribution of the Ryoke-Abukuma metamorphic belt and approximate sample locations.

measurements on these samples, and $\mathrm{K}-\mathrm{Ar}$ and $\mathrm{Rb}-\mathrm{Sr}$ ages are given by Ozima et al. (1967) and UeNo et al.(1969).

\section{Analytical Procedures}

Zircon populations were isolated by conventional procedures and, in some cases, split into size fractions using Nylon mesh screens. Lead and uranium were extracted by standard borax fusion and anion exchange methods, followed by dithizone purification of lead. Data were taken with a Consolidated Electrodynamics 12-inch solid source mass spectrometer equipped with an electron multiplier.

One complete zircon analysis was performed for each rock sample (Table 1). A "complete" analysis consists of a determination of the isotopic composition of lead in the zircon and measurements of the concentration of lead and uranium by isotope dilution. Each observed lead composition was corrected for common lead using the feldspar lead from that rock (Shimizu, 1967). Daughter-parent atom ratios for the complete analyses have an estimated precision of $2 \%$ or better.

Three additional analyses are given (Table 2 ) in which the isotopic composition of lead could not be measured, either because of insufficient yield or because of 


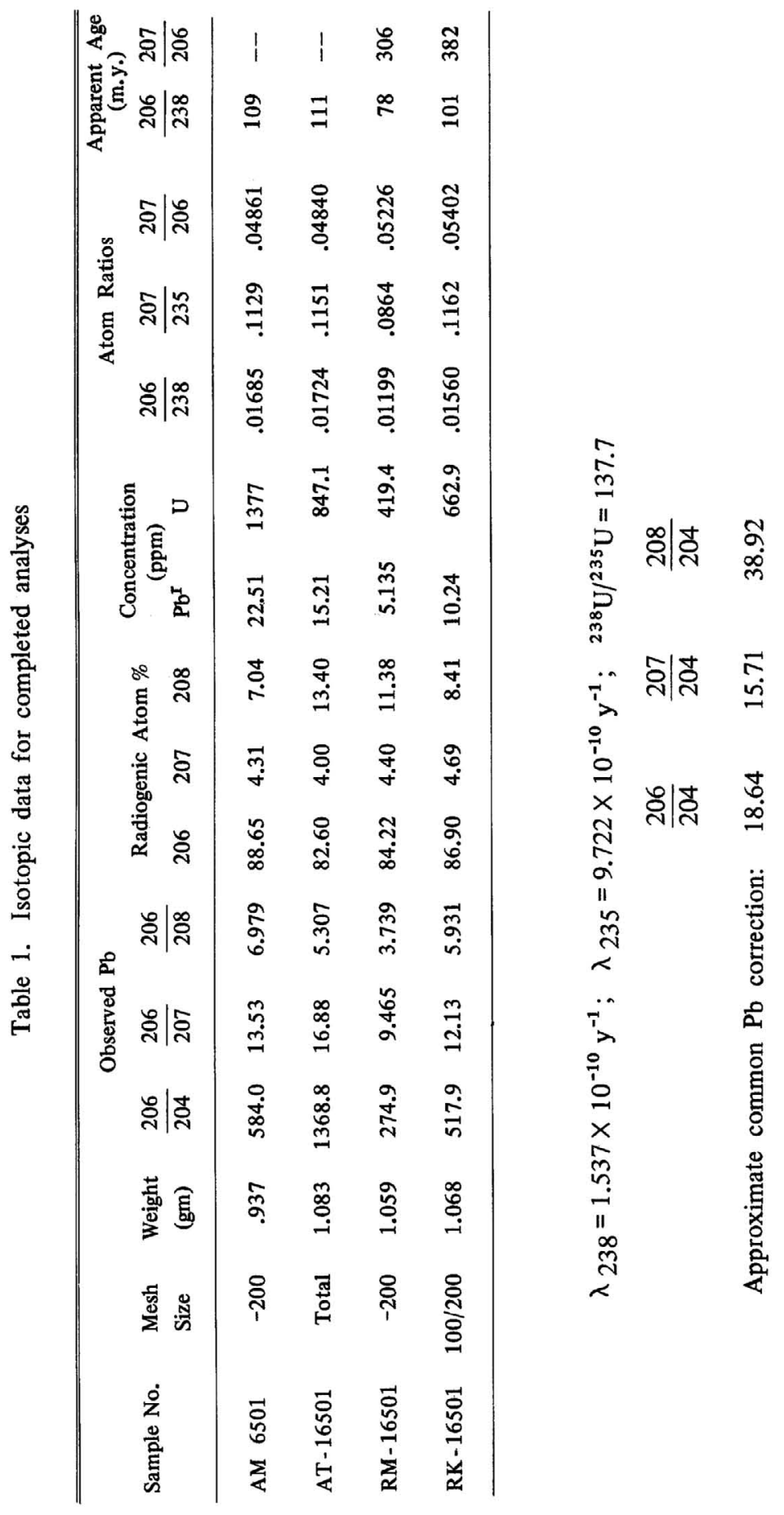




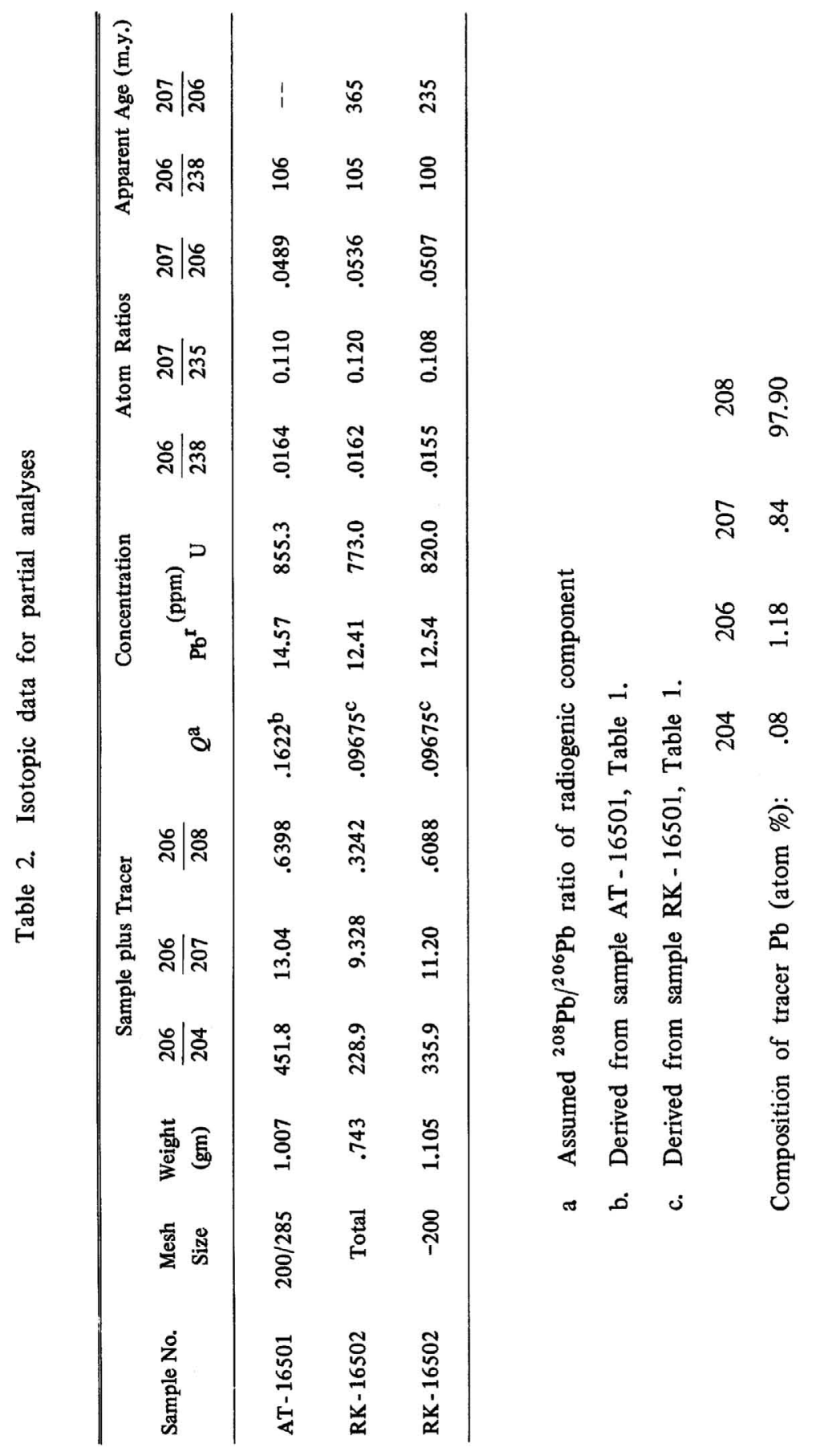


excessive impurities that inhibited emission of lead in the spectrometer. Ages have been calculated for these analyses by using the isotopic composition of the isotope dilution mixture of sample plus tracer lead, and assuming a value for the ${ }^{208} \mathrm{~Pb} /{ }^{206} \mathrm{~Pb}$ ratio of the radiogenic lead in the sample. This procedure increases the uncertainty in the ${ }^{207} \mathrm{~Pb} /{ }^{206} \mathrm{~Pb}$ ratio by about $1 \%$ and adds $4-5 \%$ to the uncertainty in the ${ }^{206} \mathrm{~Pb} /$ ${ }^{238} \mathrm{U}$ ratio.

\section{$\mathrm{U}-\mathrm{Pb}$ SYSTEMATICS}

We review here certain features of the decay systematics which affect the interpretation of $\mathrm{U}-\mathrm{Pb}$ analyses from geologically young samples. Let $X, Y, Z$ stand for the ratios ${ }^{206} \mathrm{~Pb} /{ }^{238} \mathrm{U},{ }^{207} \mathrm{~Pb} /{ }^{235} \mathrm{U}$, and ${ }^{207} \mathrm{~Pb} /{ }^{206} \mathrm{~Pb}$, and let $T_{1}, T_{2}, T_{3}$ stand for the ages calculated from these ratios according to the usual decay equations. Only two of the three ages are independent. Phenomenologically, $T_{1}$ and $T_{2}$ are the independent ages because they are based on separate decay schemes. The constancy of ${ }^{238} U /{ }^{235} U$ in nature then permits $T_{3}$ to be calculated as a derivative age. Analytically, however, it is more convenient to regard $T_{1}$ and $T_{3}$ as the independent ages. This is so because the determination of $Z$ requires only an isotope ratio measurement whereas the determination of $X$ (or $Y$ ) requires a measurement of concentration ratios, and the principal sources of error in these two kinds of measurement are fundamentally different. Also, $T_{1}$ is preferred over $T_{2}$ because ${ }^{238} \mathrm{U}$ (and hence ${ }^{206} \mathrm{~Pb}$ ) is considerably more abundant than ${ }^{235} \mathrm{U}$ (and hence ${ }^{207} \mathrm{~Pb}$ ), so that $X$ is less sensitive than $Y$ to errors in isotope abundance measurements.

A concordant system is characterized by the equalities $T_{1}=T_{2}=T_{3}$. Discordant systems may be divided into two classes. The first, which may be called the apparent $U$ loss case (though $U$ loss need not be the actual mechanism of discordance) is characterized by $T_{1}>T_{2}>T_{3}$. The second, which may be called the apparent $\mathrm{Pb}$ loss case (though $\mathrm{Pb}$ loss need not be the actual mechanism), is characterized by $T_{1}<T_{2}<$ $T_{3}$. In either case, the quantity $\left|T_{3}-T_{1}\right|$ is the most sensitive indicator of discordance, and further illustrates the desirability of focusing attention on $T_{1}$ and $T_{3}$ rather than $T_{2}$.

Because ${ }^{235} \mathrm{U}$ has a short half life, its initial abundance relative to ${ }^{238} \mathrm{U}$ in $\mathrm{U}$ bearing minerals decreases markedly with decreasing sample age. In Precambrian rocks the decays of both ${ }^{238} U$ and ${ }^{235} U$ have contributed significantly to the accumulated radiogenic lead, but in a $100 \mathrm{~m}$.y. old rock almost all the isotopic evolution is controlled by the decay of ${ }^{238} \mathrm{U}$. Hence, with decreasing age, small uncertainties in measuring the abundance of radiogenic ${ }^{207} \mathrm{~Pb}$ generate increasingly large uncertainties in $T_{2}$ and $T_{3}$. This effect is most pronounced for $T_{3}$. Suppose, for example, that $Z$ is measured with an uncertainty of $1 \%$, then the resulting uncertainty in $T_{3}$ is $2 \%$ at 1,000 m.y., but as much as $25 \%$ at $100 \mathrm{~m}$.y. Consequently the numerical value of $T_{3}$ is of little use for geochronology if the sample is geologically young. The value of 
$Z$, however, remains useful because analytical errors in measuring this ratio increase only slightly with decreasing age.

We believe that discordance in young $\mathrm{U}-\mathrm{Pb}$ systems is best evaluated by cornparing the observed value of $Z$ with the value predicted from $T_{1}$ on the assumption of concordance. Unless the data are numerous or of high precision, a sample is considered to be concordant within analytical and half life errors (BANKS and SILVER, $1966)$ if the observed and predicted values of $Z$ agree to $2 \%$ or better. It follows from this criterion that concordant samples have only one analytically significant age, namely $T_{1}$. In the data given in this paper we report $T_{3}$ only if it departs from $T_{1}$ by an amount well in excess of analytical errors. $T_{2}$ is not reported at all because it contributes no new information.

\section{Discussion}

\section{Abukuma Plateau}

The completed analyses of zircons from the Tabito and Miyamoto granodiorites (Table 1) are identical within experimental error and suggest that intrusion and crystallization of the "older" granodiorites in this region occurred during a brief interval approximately 110 m.y. ago. The partial analysis of AT-16501 (Table 2) is in good agreement if allowance is made for the greater uncertainty in calculating ages for this sample. Additional zircon work might reveal small age differences among the various plutons of the older group, but as yet we have no evidence for the widely different ages suggested by $\mathrm{Rb}-\mathrm{Sr}$ analyses (UENO et al., 1969).

The rediogenic ${ }^{207} \mathrm{~Pb} /{ }^{206} \mathrm{~Pb}$ ratios of these zircons are not significantly different from the value of 0.0481 expected for 110 m.y. old systems on the basis of the accepted uranium constants. Consequently there is no evidence for inherited $\mathrm{Pb}$ that might cause the ${ }^{206} \mathrm{~Pb} /{ }^{238} \mathrm{U}$ ages to be too high. By analogy with the behavior of discordant Precambrian zircons, one might suppose that the ${ }^{206} \mathrm{~Pb} /{ }^{238} \mathrm{U}$ ages could be lower than the true ages. However, the integrated radiation damage sustained by Cretaceous zircons is rather small and is unlikely to result in more than a few percent lead loss except in abnormally radioactive samples. Thus, we believe that 110 m.y. is a close approximation to the actual time of crystallization of these granodiorites.

\section{Shidara Area}

Zircons from the Shidara granodiorites are remarkable for having radiogenic ${ }^{207} \mathrm{~Pb} /{ }^{206} \mathrm{~Pb}$ ratios $5-10 \%$ higher than would be expected from their ${ }^{206} \mathrm{~Pb} /{ }^{238} \mathrm{U}$ apparent ages (the expected ratios are approximately 0.0475 at $80 \mathrm{~m} . \mathrm{y}$. and 0.0479 at $100 \mathrm{~m} . \mathrm{y}$.). The differences are too large to be attributed to analytical errors, errors in half-lives, or the common lead correction, and must therefore, reflect the presence of anomalously old radiogenic lead in these zircons. Such lead might originate from residual refractory material in the magma reservoir or from xenocrysts acquired during em- 
placement of the granodiorites, and we shall call it the "inherited" component. The remainder of the radiogenic lead (generated since the time the granodiorites crystallized) we shall call the "primary" component. Examination of the zircon populations showed no distinctive grains or grain cores with which the inherited component might be associated; therefore either the inherited component is distributed pervasively throughout the entire zircon populations or it is located in specific zircon phases that are morphologically indistinguishable from unaffected zircons.

The few data we have obtained are not sufficient to derive unique ages for the primary and inherited components. However, the observed isotope ratios from each sample define a functional relationship between the age of its primary component and the ${ }^{207} \mathrm{~Pb} /{ }^{206} \mathrm{~Pb}$ ratio of its inherited component, and from these relationships certain limiting statements can be made.

We use the notation described previously, and in addition let the subscripts $m, p$, and $i$ designate quantities actually measured $(m)$, quantities associated with the primary component $(p)$, and quantities associated with the inherited component $(i)$. It is convenient to assign all the measured uranium to the primary component, so that ${ }^{238} \mathrm{U}_{m}={ }^{238} \mathrm{U}_{p}$.

With this convention the inherited component is to be regarded solely as an initial lead whose isotopic composition does not change subsequent to its incorporation in the primary system. Material balance requires that

$$
X_{m}=\frac{{ }^{206} \mathrm{~Pb}_{m}}{{ }^{238} \mathrm{U}_{m}}=\frac{{ }^{206} \mathrm{~Pb}_{p}+{ }^{206} \mathrm{~Pb}_{i}}{{ }^{238} \mathrm{U}_{p}}
$$

and

$$
Z_{m}=\frac{{ }^{207} \mathrm{~Pb}_{m}}{{ }^{206} \mathrm{~Pb}_{m}}=\frac{{ }^{207} \mathrm{~Pb}_{p}+{ }^{207} \mathrm{~Pb}_{i}}{{ }^{206} \mathrm{~Pb}_{p}+{ }^{206} \mathrm{~Pb}_{i}}
$$

By suitably arranging terms and solving these two equations simultaneously, it can be shown that

$$
Z_{i}=\frac{X_{m} Z_{m}-X_{p} Z_{p}}{X_{m}-X_{p}}
$$

$X_{p}$ and $Z_{p}$ are related to the age of the primary component $\left(T_{p}\right)$ by the standard decay equations (we assume the primary component is exactly concordant). The inherited component, however, has not evolved isotopically since the time $T_{p}$; hence its apparent age $\left(T_{i}\right)$ must be obtained from the modified decay equation

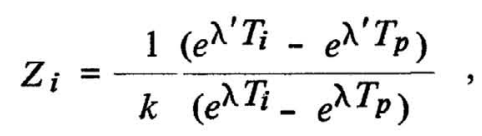


where $\lambda$ and $\lambda^{\prime}$ are the decay constants of ${ }^{238} \mathrm{U}$ and ${ }^{235} \mathrm{U}$, respectively, and $k$ is the ratio ${ }^{238} \mathrm{U} /{ }^{235} \mathrm{U}$.

Figure 2 portrays the relationship between $T_{p}$ and $T_{i}$ for the two completed zircon analyses from the Shidara granodiorites. These curves have the following significance. Suppose the sample points are placed on a concordia diagram (WETHERILL, 1956) and suppose that all possible chords are drawn through each sample point. Then the values of $T_{i}$ and $T_{p}$ given by the curves in Fig. 2 represent the upper and lower intersections of these chords with the concordia curve.

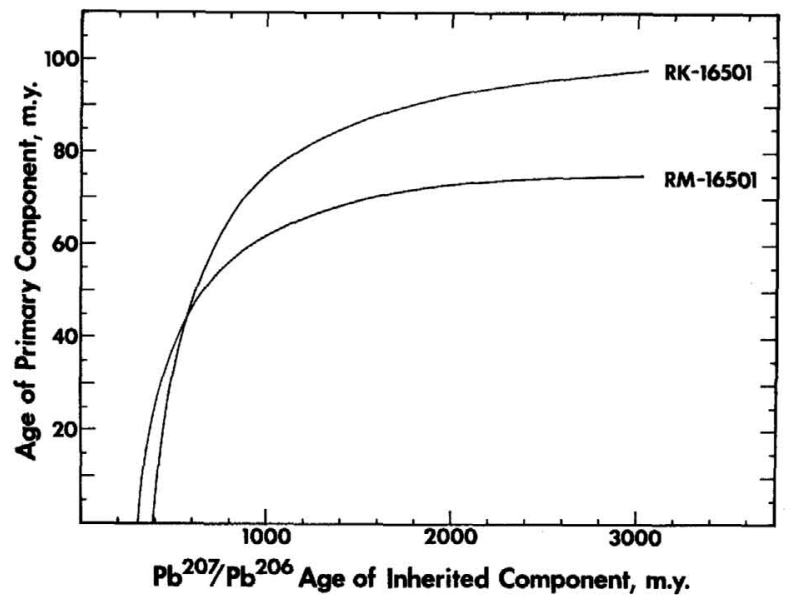

Fig.2. Relationship between the age of the primary component and the ${ }^{207} \mathrm{~Pb} /{ }^{206} \mathrm{~Pb}$ apparent age of the inherited component for the Shidara zircon samples.

One possible interpretation is that the Kiyosaki and Mitsuhashi granodiorites crystallized nearly simultaneously and contain an isotopically similar inherited component. This is equivalent to saying that the sample points lie on the same chord in the concordia diagram, and corresponds to the intersection of the two curves in Fig. 2 . Thus, according to this hypothesis, the age of primary crystallization would be about $45 \mathrm{~m} . \mathrm{y}$. and the inherited component would have an apparent age of about $600 \mathrm{~m} . \mathrm{y}$. These ages are undoubtedly low estimates, however, because $\mathrm{K}-\mathrm{Ar}$ and $\mathrm{Rb}-\mathrm{Sr}$ data indicate a minimum age of about $70 \mathrm{~m} . \mathrm{y}$. for both rocks (OzIMA et al., 1967). A 70 m.y. primary age for the Mitsuhashi granodiorite requires that the inherited component be at least $1,400 \mathrm{~m}$.y. old. If, in turn, the inherited component in the Kiyosaki granodiorite is also at least $1,400 \mathrm{~m}$.y. old, then the primary age of this rock must be at least $10 \mathrm{~m} . \mathrm{y}$. greater than the primary age of the Mitsuhashi granodiorite.

Tentative support for the interpretation that the inherited component is much older than $600 \mathrm{~m} . \mathrm{y}$. is given by the partial analyses of RK-16502 (Table 2). Although 
these data must be interpreted with caution, the ${ }^{207} \mathrm{~Pb} /{ }^{206} \mathrm{~Pb}$ ratios, which are relatively insensitive to the assumed value for the ${ }^{208} \mathrm{~Pb} /{ }^{206} \mathrm{~Pb}$ ratio, appear to differ from each other by a significant amount, while the more sensitive ${ }^{206} \mathrm{~Pb} /{ }^{238} \mathrm{U}$ ratios are not analytically distinguishable and, in fact, agree closely with the completed analysis of RK-16501. This is possible only if the inherited component constitutes a very small proportion of the total $\mathrm{Pb}$ but has a high (i.e., "old") ${ }^{207} \mathrm{~Pb} /{ }^{206} \mathrm{~Pb}$ ratio.

Our best estimate of the significance of these data, therefore, is that the Mitsuhashi and Kiyosaki granodiorites were emplaced at two distinctly different times, the former about 70-75 m.y. ago and the latter perhaps 80-90 m.y. ago; and that the zircons in both rocks contain anomalous radiogenic lead probably at least $1,400 \mathrm{~m}$.y. old. Considerable care must be taken in attaching geochronologic significance to the age of the inherited component. The calculated age is an apparent age and may not represent the actual age of any rock system. There are two reasons for this: 1) the inherited component may be a mixture from several sources of different ages, and/or 2) the inherited component may have been derived from U-Pb systems which were discordant prior to their incorporation in the Shidara granodiorites. The apparent age of the inherited component is therefore at best only a minimum estimate for the age of the oldest $\mathrm{U}-\mathrm{Pb}$ system contributing to it.

The source of the inherited component is an intriguing puzzle. One possibility is that the granodiorites originated in a Precambrian basement. Kurasawa (1968) suggested a similar explanation for abnormally primitive lead isotopes in the Tertiary volcanic rocks from Dogo of the Oki Islands. Alternate possibilities are that the anomalous lead was derived from the mantle, or from detrital materials in metasedimentary wall rocks. Regardless of where the inherited component originated, its persistence as an identifiable component in these rocks has important consequences for the behavior and evolution of lead isotopes, as discussed by DoE (1967).

\section{SUMMARY}

Zircons from two granodiorites of the Abukuma Plateau contain normal U-Pb isotope systems indicative of crystallization during a brief interval approximately 110 m.y. ago. In contrast, zircons from the granodiorites of the Shidara area contain $\mathrm{U}-\mathrm{Pb}$ isotope systems characterized by the presence of an anomalously old radiogenic lead component. A unique solution for the primary age of the granodiorites and the age of the inherited component is not possible, but the available data indicate that the anomalous lead is at least $600 \mathrm{~m}$.y. old and probably more than $1,400 \mathrm{~m}$.y. old. On this basis the two granodiorites probably differ in age by at least $10 \mathrm{~m}$.y., one being emplaced 70-75 m.y. ago and the other 80-90 m.y. ago. The existence of inherited lead in the Shidara zircons poses fundamental problems, among which are: 1) the source of such lead, 2) the method by which it was incorporated in the granodiorites, and 3) the significance of this behavior for the evolution of lead isotopes. 


\section{ACKNOWLEDGEMENTS}

This work was sponsored by the U.S.-Japan Cooperative Science Program through Grant No.GF- 215 of the U.S. National Science Foundation and a grant from the Japan Society for the Promotion of Science. We are especially grateful to Professor H. Kuno for his advice and support.

\section{REFERENCES}

BANKS, P. O., and SILVER, L. T. (1966) Evaluation of the decay constant of uranium 235 from lead isotope ratios. J. Geophys. Res. 71, 4037-4046.

DOE, B. R. (1967) The bearing of lead isotopes on the source of granitic magma. J. Petrology 8, 51-83.

GORAI, M. (1944) Petrological study on the plutonic rocks of Gosaisho-Takanuki district, southern Abukuma Plateau. Mem. Fac. Sci., Kyushu Imp. Univ., Ser. D. 2, 239-321.

KoIDE, H. (1958) Dando granodiorite intrusives and their associated metamorphic complex. Japan Soc. for the Promotion of Science, 1-311.

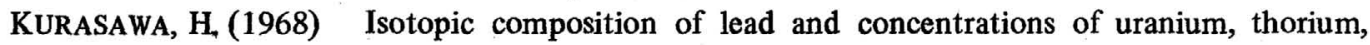
and lead in volcanic rocks from Dogo of the Oki Islands, Japan. Geochem. J. 2, 11-28.

Ozima, M., UENO, N., SHIMIZU, N., and KUNO, H. (1967) Rb-Sr and K-Ar isotopic investigations of Sidara granodiorites and the associated Ryoke metamorphic belt, central Japan. Japanese J. Geol. Geog., 38, 159-162.

SHIMIZU, N. (1967) Lead isotopic studies on granitic rocks of the Abukuma and Shidara areas in the Ryoke-Abukuma metamorphic belt, central Japan. Ph. D. Thesis, University of Tokyo. 35-44.

UENo, N., OZIMA, M. and ONO, A. (1969) Rb-Sr and K-Ar isotopic investigations of granodiorites and associated metamorphic rocks from the Ryoke-Abukuma metamorphic belt. Geochem. J. 3,

WATANABE, I., GoRAI, M., KURODA, Y., ONO, Y., and TOGaWA, T. (1955) Igneous activities of the Abukuma Plateau, Chikyu-Kagaku, 24, 1-11 (in Japanese).

WETHERILL, G. W. (1956) An interpretation of the Rhodesia and Witwatersrand age patterns. Geochim. Cosmochim. Acta 9, 290-292. 